\title{
Three-dimensional Dixon fat-water separated breath-held imaging of myocardial delayed enhancement Manojkumar Saranathan ${ }^{* 1}$ and James F Glockner ${ }^{2}$
}

Address: ${ }^{1}$ GE Healthcare, Rochester, MN, USA and ${ }^{2}$ Mayo Clinic, Rochester, MN, USA

* Corresponding author

from 13th Annual SCMR Scientific Sessions

Phoenix, AZ, USA. 21-24 January 2010

Published: 21 January 2010

Journal of Cardiovascular Magnetic Resonance 2010, I2(Suppl I):PI02 doi:I0.I I86/I532-429X-I2-SI-PI02

This abstract is available from: http://jcmr-online.com/content/I2/SI/PI02

(C) 2010 Saranathan and Glockner; licensee BioMed Central Ltd.

\section{Introduction}

Myocardial delayed enhancement (MDE) imaging of infarction is commonly performed using an inversion-recovery (IR) two-dimensional (2D) breath-held fast gradient recalled echo (FGRE) pulse sequence. Three-dimensional (3D) imaging can improve scanning efficiency by acquiring the desired volume in a single breath-hold. Fat suppression could greatly improve visualization of epicardial enhancement (which occurs in transmural myocardial infarction and myocarditis) as well as pericardial enhancement.

\section{Purpose}

To investigate a novel Dixon fat-water separated 3D breath-hold technique for fat suppressed imaging of MDE.

\section{Methods}

An ECG-gated dual-echo bipolar-readout 3DFGRE pulse sequence was developed. High receiver bandwidths enabled placement of opposed- and in-phase echoes at 2.4/ $4.8 \mathrm{~ms}$, achieving compact TRs. Elimination of explicit fat suppression enabled use of a novel k-space segmentation scheme that is efficient and has desirable motion insensitivity properties. Radial fanbeam k-space segmentation of an elliptical $\mathrm{k}_{\mathrm{y}}-\mathrm{k}_{\mathrm{z}}$ region (corners skipped) was employed for efficient coverage of k-space, enabling 3D data acquisition in a single breath-hold. Within each fanbeam, kspace points were acquired in the order of increasing kr. In each R-R interval, a non-selective $180^{\circ}$ pulse followed by an inversion time (TI) delay of $200-250 \mathrm{~ms}$ preceded data acquisition at $\sim 300 \mathrm{~ms}$ (32-36 points). A self-calibrated parallel imaging scheme with acceleration factor of 2.5 in the phase encoding direction yielded an overall breathholding time of 22-25 s. A robust region-growing based phase-corrected 2-point Dixon reconstruction algorithm of Ma et al. was used. Patients with known or suspected myocardial infarction, myocarditis, pericarditis, or nonischemic cardiomyopathy were imaged after informed consent on a 1.5 T GE SIGNA scanner using an 8-channel phased array coil. Imaging was performed approximately $10-15$ minutes after bolus injection of $0.2 \mathrm{mmol} / \mathrm{kg}$ of Gadolinium DTPA contrast agent. The 3D Dixon FGRE scan immediately followed the IR prepared 2D FGRE acquisition.

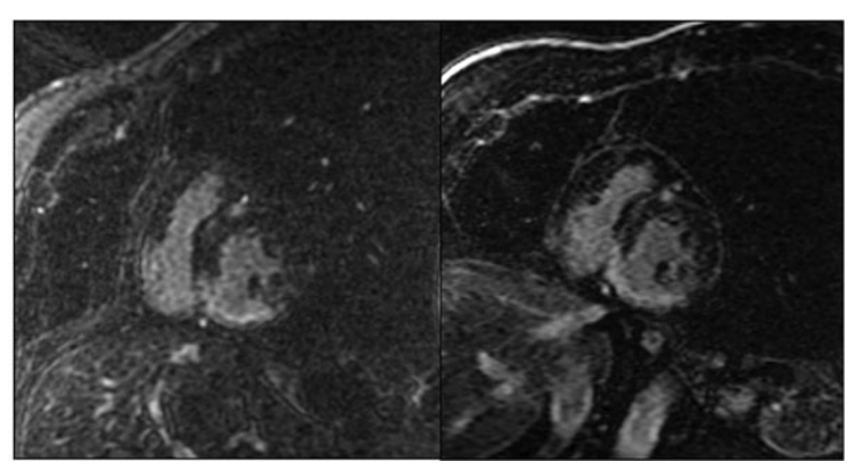

Figure I

Short axis 2D MDE (left) and 3D Medal MDE (right) images in patient with inferior/inferoseptal infarct demonstrate transmural delayed enhancement. 


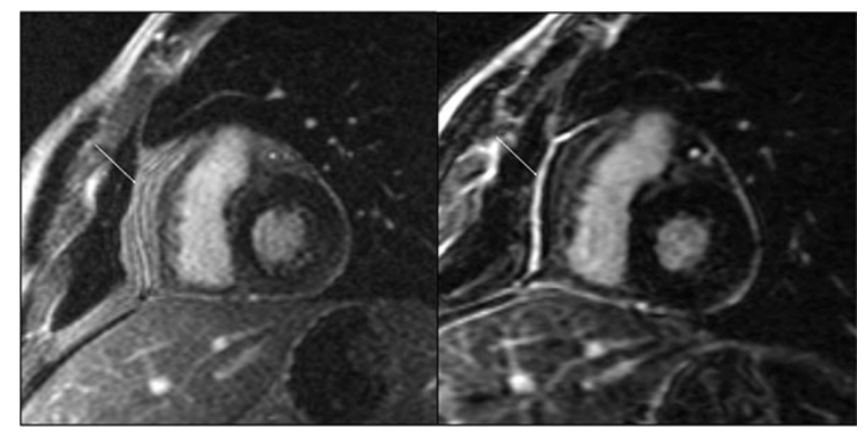

Figure 2

Short axis 2D MDE (left) and 3D Medal MDE images (right) in a patient with pericarditis. Pericardial enhancement is more clearly deomnstrated in the fat-suppressed Medal MDE image (right).

\section{Results}

Figure 1 compares conventional 2D MDE with 3D Dixon MDE in a patient with an inferior infarct demonstrating better SNR and spatial resolution of the 3D sequence. Figure 2 compares conventional 2D MDE and 3D Dixon MDE in a patient with pericarditis clearly showing improved visualization of pericardial enhancement in the 3D Dixon sequence.

\section{Conclusion}

A technique capable of providing full heart coverage in a single 3D breath-held acquisition was validated. The use of Dixon based fat-water separation makes the technique immune to Bo inhomogeneities, improving SNR as well as fat suppression. The novel radial fan-beam k-space segmentation enabled acquisition of a $3 \mathrm{D}$ slab in a short breath-hold.
Publish with Bio Med Central and every scientist can read your work free of charge

"BioMed Central will be the most significant development for disseminating the results of biomedical research in our lifetime. "

Sir Paul Nurse, Cancer Research UK

Your research papers will be:

- available free of charge to the entire biomedical community

- peer reviewed and published immediately upon acceptance

- cited in PubMed and archived on PubMed Central

- yours - you keep the copyright

Submit your manuscript here:

http://www.biomedcentral.com/info/publishing_adv.asp
BioMedcentral 